\title{
MUSCLE ACTIVITY AND THE LOSS OF ELECTRICAL COUPLING BETWEEN STRIATED MUSCLE CELLS IN XENOPUS EMBRYOS ${ }^{1}$
}

\author{
DAVID L. ARMSTRONG,, ${ }^{2,3}$ LUCA TURIN, ${ }^{3}$ AND ANNE E. WARNER \\ Department of Anatomy and Embryology, University College, London, WCIE 6BT, England
}

Received November 18, 1982; Revised January 11, 1983; Accepted January 31, 1983

\begin{abstract}
The gap junctions between embryonic striated muscle cells are lost during development. The time course of their elimination has been examined with electrophysiological techniques in myotomes of Xenopus laevis embryos. Gap junctions were detected by the passage of electrotonic current or the fluorescent dye, Lucifer Yellow, from one muscle cell to another. These tracers only spread to neighboring cells when injected intracellularly.

All the muscle cells are electrically coupled at stage 24 when neuromuscular transmission begins, but normally many cells become uncoupled during the next $48 \mathrm{hr}$. In contrast, the muscle cells remain electrically coupled if neuromuscular transmission is blocked during that period with tricaine or $\alpha$-bungarotoxin. When muscle activity recovers, the loss of coupling resumes. Once the coupling has disappeared, neuromuscular blockade does not restore it. Muscle contraction is blocked during development in a mutant of Xenopus, even though the muscle cells remain electrically excitable. After stage 32 in these immobile embryos, the muscle cells are stimulated repeatedly by regular bursts of neural activity. Although they never contract, the mutant muscle cells become uncoupled at the same time as the muscle cells in normal embryos.

The results suggest that some consequence of repeated cholinergic activation, other than contraction, stimulates the loss of gap junctions between striated muscle cells during development. The elimination of gap junctions may be required for neural control of subsequent muscle differentiation.
\end{abstract}

Developing striated muscle cells are electrically coupled to one another by a direct, low-resistance pathway (Dennis, 1975; Blackshaw and Warner, 1976; Dennis et al., 1981). Gap junctions have been identified as the morphological correlate of such electrical coupling, and they connect striated muscle cells during development in many vertebrate embryos (Kelley and Zacks, 1969; Hayes, 1975; Keeter et al., 1975; Blackshaw and Warner, 1976; Schmalbruch, 1982). Gap junctions evidently allow small metabolites as well as ions to pass directly from the cytoplasm of one embryonic muscle cell to another (Kalderon et al., 1977), but their role in myogenesis remains to be discovered. Adult skeletal muscle fibers are not electrically coupled (Dennis, 1975; Dennis et al., 1981); the gap junctions disappear after neuromuscular transmission matures (Keeter et al., 1975; Schmalbruch,

\footnotetext{
${ }^{1}$ This work was supported by the British Medical Research Council and the Muscular Dystrophy Association of America. We are also grateful for the gifts of Lucifer Yellow from Dr. Walter Stewart, $\alpha-$ bungarotoxin from Dr. Stuart Bevan, and mature immobile heterozygotes from Dr. Anne Droin.

${ }^{2}$ To whom correspondence should be addressed at his new address.

${ }^{3}$ Present address: Station Zoologique, 06230 Villefranche-sur-mer, France.
}

1982). In this paper we consider the possibility that muscle activity precipitates their elimination.

Harrison (1904) introduced the use of drugs that block neuromuscular transmission to investigate the role of activity in muscle development. Subsequently, several features of nerve and muscle differentiation have been shown to depend on functional synaptic transmission (reviewed by Harris, 1981). For example, the extrasynaptic acetylcholine receptors on embryonic skeletal muscle also disappear after muscle activity begins (Diamond and Miledi, 1962; Dennis and Ort, 1977), but their elimination can be delayed while neuromuscular transmission is blocked pharmacologically (Gordon and Vrbová, 1975; Burden, 1977). Similar observations are reported here for the gap junctions between developing muscle cells. A preliminary report of some of the results has been published (Armstrong and Warner, 1980).

\section{Materials and Methods}

Xenopus laevis embryos were obtained from mature pairs of toads by injections of chorionic gonadotropin (Organon, Ltd.). Normal embryos were staged according to the system of Nieuwkoop and Faber (1956) and reared in water from the mains at room temperature. Just before 
recording, embryos were anesthetized briefly in tricaine, removed from the vitelline membrane, decerebrated, and transferred to Ringer's solution with the following composition, (in millimoles per liter): $\mathrm{NaCl}, 110 ; \mathrm{KCl}, 2$; $\mathrm{CaCl}_{2}, 4 ; \mathrm{MnCl}_{2}, 2$; HEPES (4-(2-hydroxyethyl)-1-piperazine-ethanesulfonic acid), $5 \mathrm{~mm}, \mathrm{pH}$ 7.3. Manganese ions were included to prevent neurally evoked muscle contractions. The preparation was pinned out on Sylgard (Dow Corning, 184) with tungsten wire pins and viewed through a binocular dissecting microscope. The overlying ectoderm was removed from the myotomes with glass needles and fine forceps. The myotomes develop in a rostrocaudal sequence, and myotome formation continues throughout the life of the tadpole. Consequently, the timing of muscle differentiation and uncoupling may vary among the myotomes. We have restricted our observations to the 12 most rostral post-otic myotomes since these are formed before any experiments were begun.

Electrical measurements. Two muscle cells in adjacent myotomes were each penetrated with a glass microelectrode. The micropipettes were filled with $0.8 \mathrm{M}$ potassium citrate and had resistances between 50 and 70 megohms. Current was injected into one cell, and the membrane potential of the other was recorded differentially with conventional electrophysiological techniques. The current was measured as the voltage drop across a 1-megohm resistor between the bath and earth. Current pulses of 25 $\mathrm{nA}$ or less lasted about $1 \mathrm{sec}$ and were adjusted to produce steady-state hyperpolarizing responses smaller than $10 \mathrm{mV}$. No voltage responses were detected when similar currents were passed extracellularly. In practice the microelectrodes were several cells apart, and many of the intervening cells must have been coupled for current to spread between them.

One can make a rough estimate of the amount of coupling by dividing the voltage change in one cell with the current applied to the other cell. In circuit theory this ratio $(\mathrm{mV} / \mathrm{nA})$ is referred to as a transfer resistance, but the term mutual resistance has been used here to emphasize that its value is determined by the electrical properties of the entire cell membrane and not just the gap junction (cf. Detwiler and Hodgkin, 1979). For example, if a cell were damaged by the electrode, its membrane resistance might be sufficiently smaller than the gap junction's resistance to make the cells appear uncoupled. This possibility was avoided by studying only muscle cells with membrane potentials more negative than $-80 \mathrm{mV}$. Since extracellular voltage changes were never detected with currents smaller than $25 \mathrm{nA}$, values of mutual resistance greater than $0.04 \mathrm{mV} / \mathrm{nA}$ can only be explained by a direct pathway for current flow between the cells. Cell fusion might provide such a pathway, but in Xenopus myotomes the muscle cells remain mononucleate until stage 45 (Muntz, 1975).

Fluorescence measurements. Lucifer Yellow (Stewart, 1978) was iontophoresed into cells by repeating negative current pulses ( $5 \mathrm{nA} ; 1 \mathrm{sec}$ ) at $0.5 \mathrm{~Hz}$ for several minutes. The microelectrodes were filled with a $3 \%$ solution $(\mathrm{w} / \mathrm{v})$ of the dye in $0.1 \mathrm{M} \mathrm{LiCl}$. The spread of fluorescence was observed through a high-pass filter (50 $\mathrm{nm}$ cut-off) on a Zeiss microscope with a $50-\mathrm{W}$ mercury vapor lamp and a BG 12 excitation filter. At early stages, autofluorescence from the numerous yolk granules precluded dye-coupling studies. The amount of dye injected was limited by the duration of the penetration and the modest currents required to avoid electronic saturation with high-resistance micropipettes. These factors may have been responsible for some of the variability in the extent of dye coupling. None of the muscle cells were filled with dye when it was released extracellularly.

Pharmacological studies. Muscle activity was suspended during development with ethyl $m$-aminobenzoate methane sulfonate (tricaine, 1 to $2 \mathrm{mM}$ ). Tricaine rapidly crosses the embryos' external membranes and interrupts neuromuscular transmission. Tricaine probably acts presynaptically. When tricaine was applied at these concentrations to adult frog sciatic nerves, the extracellularly recorded compound action potential was abolished $(n=$ 2). Intact embryos were exposed to tricaine for varying periods during development. Most of the embryos resumed swimming within 30 min after removing the tricaine. Although tricaine noticeably slowed their development, some tadpoles were raised up to metamorphosis after their return to water. The experimental embryos were allowed to recover momentarily before recording to make sure they were still alive. Superficially normal embryos were then re-anesthetized and prepared for recording in the standard Ringer's solution without tricaine, exactly as described above for the controls.

Neuromuscular transmission was blocked postsynaptically with $\alpha$-bungarotoxin which binds irreversibly to the cholinergic receptor on skeletal muscle (Chang and Lee, 1963; Miledi and Potter, 1971). The muscle cells were exposed to toxin at stage 24 by opening a flap in the ectoderm above the myotomes while the embryos were immersed in Ringer's solution which contained $0.1 \mu \mathrm{M}$ $\alpha$-bungarotoxin. After $2 \mathrm{hr}$, the embryos were transferred to diluted Ringer's solution (1:9), also with $0.1 \mu \mathrm{M}$ toxin, where the ectoderm gradually healed. At the time of transfer, intracellular recording revealed no sign of spontaneous neuromuscular transmission in myotomes immediately underneath the flap, and embryos were discarded if they showed any movement. Two hours later still, the embryos were returned to water. Over the next 2 days, most of the embryos recovered, presumably because toxin-bound receptors were degraded and replaced with active ones (cf. Burden, 1977).

\section{Results}

Electrical coupling. In myotomes of early Xenopus embryos, striated muscle cells are electrically coupled to one another when neuromuscular transmission begins (Blackshaw and Warner, 1976). Figure 1, left illustrates such electrical coupling. In this case, roughly $25 \mathrm{nA}$ produced a $10-\mathrm{mV}$ response in a neighboring cell. The same current produced no response when either of the electrodes was withdrawn to a position just outside the cell; thus, the coupling cannot be explained by a restricted extracellular space. This was confirmed for every recording. Before stage 36 , similar recordings can be obtained from any two muscle cells in adjacent myotomes, although the amount of coupling measured by the mutual resistance declines steadily with age (Table I).

Figure 1, left was taken from an embryo at stage 35 , or 
about $48 \mathrm{hr}$ after fertilization. By that stage the embryos have emerged from their vitelline membrane and begun to swim freely. The recording in Figure 1, right was made on another embryo which was several hours older. Here the same current produced a much smaller response in a neighboring cell. The spontaneous quantal events which appear can be eliminated by $10 \mu \mathrm{m}$ tubocurarine. There was an inverse correlation between the amplitudes of the spontaneous events and the mutual resistance during development.

Electrical coupling was observed much less frequently in embryos that had been swimming for several hours. Figure 2 plots the incidence of electrical coupling against the stage of development. Although no coupling could be detected in most embryos after stage 38, this does not necessarily mean that all of the gap junctions have disappeared. Since the electrodes were separated by several cells during the electrical measurements, not all of the intervening cells would have to be uncoupled for current spread to be disrupted. Furthermore, the electrical measurements of coupling require that current spread both within the myotome and across myotomal borders.

Dye coupling. Gap junctions can also be identified by the intercellular transfer of dyes which do not enter the cells from the extracellular space (Payton et al., 1969). Such dye coupling should not depend on the electrical resistance of the nonjunctional membrane, and the dye can be detected wherever it spreads, at least among the surface cells. Eight individual muscle cells in six embryos were filled with Lucifer Yellow after stage 36. In every case but one the dye spread rapidly to at least one neighboring cell, but never more than three cells away from the injected cell (Fig. 3). When an electrode was placed in adjacent cells to which the dye had diffused, electrical coupling to the injected cell was always observed $(n=5 / 5)$. The presence of dye coupling between muscle cells makes it very unlikely that the electrical coupling which we observe arises solely from the close apposition of unspecialized membranes with low resistance.

Lucifer Yellow seldom spread to cells within the same myotome $(n=2 / 7)$, and neighboring cells without dye were not usually electrically coupled to the injected cell $(n=1 / 5)$. This explains the difficulty of detecting widespread electrical coupling when so many cells remain dye coupled. We observed dye coupling between abutting cells in adjacent myotomes as late as stage 45 , when the onset of cell fusion made further studies uninterpretable (Muntz, 1975). 'Taken together, electrical coupling and dye transfer studies suggest that many of the gap junctions within each myotome disappear at the same time

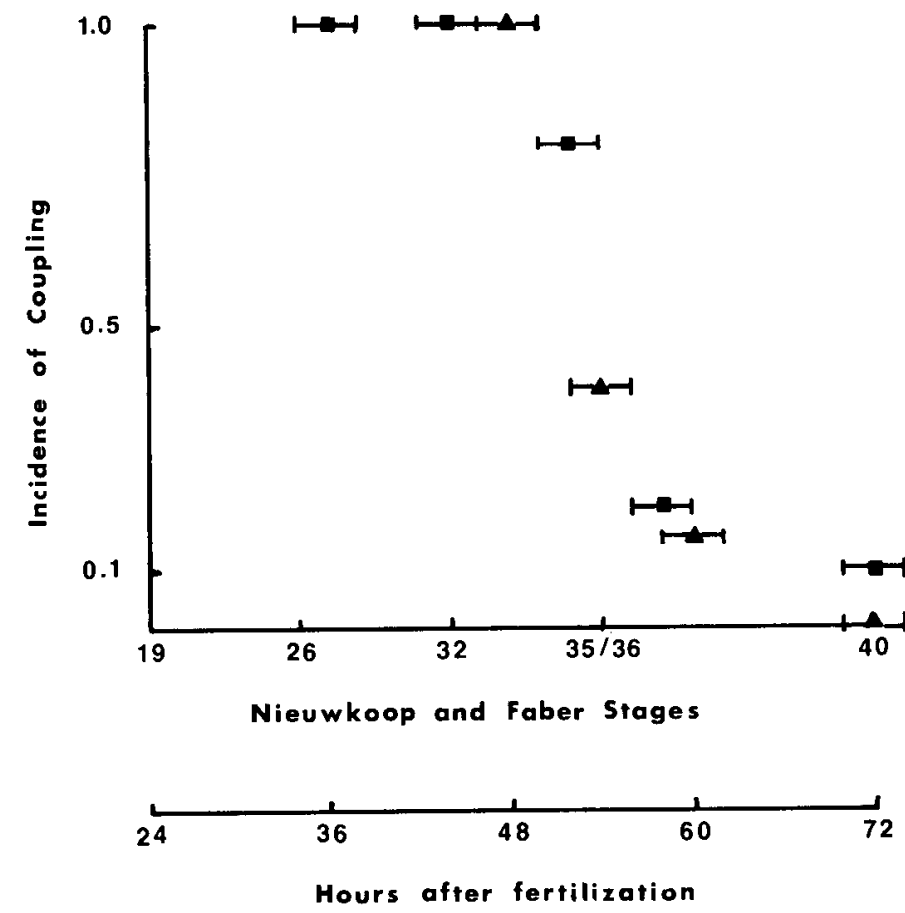

Figure 2. The incidence of electrical coupling decreases during development. Mutual resistances greater than $0.05 \mathrm{mV} / \mathrm{nA}$ were scored as coupled. Each square represents at least 10 measurements from five or more normal embryos at a particular developmental stage ( \pm 1 stage). Each triangle represents at least 5 measurements from two or more immobile embryos. Hours after fertilization are only approximate and vary with temperature.

Stage 38

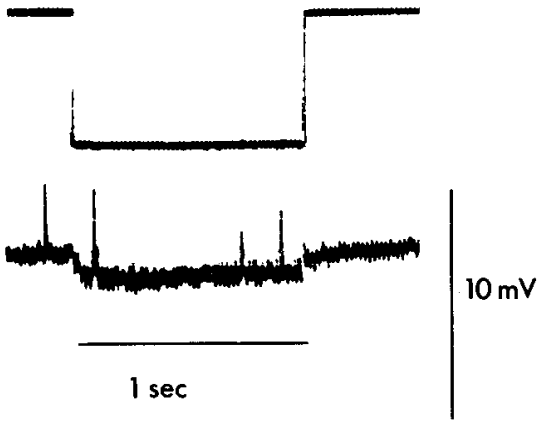

Figure 1. Electrical coupling between striated muscle cells. Recordings from two embryos at different developmental stages. Upper traces: current injected into one cell; lower traces: simultaneous voltage response in another cell in an adjacent myotome. No responses occurred when the current was released extracellularly. Roughly the same current produces a much smaller response in the older embryo, and this reduction in coupling is associated with the appearance of spontaneous quantal events. 

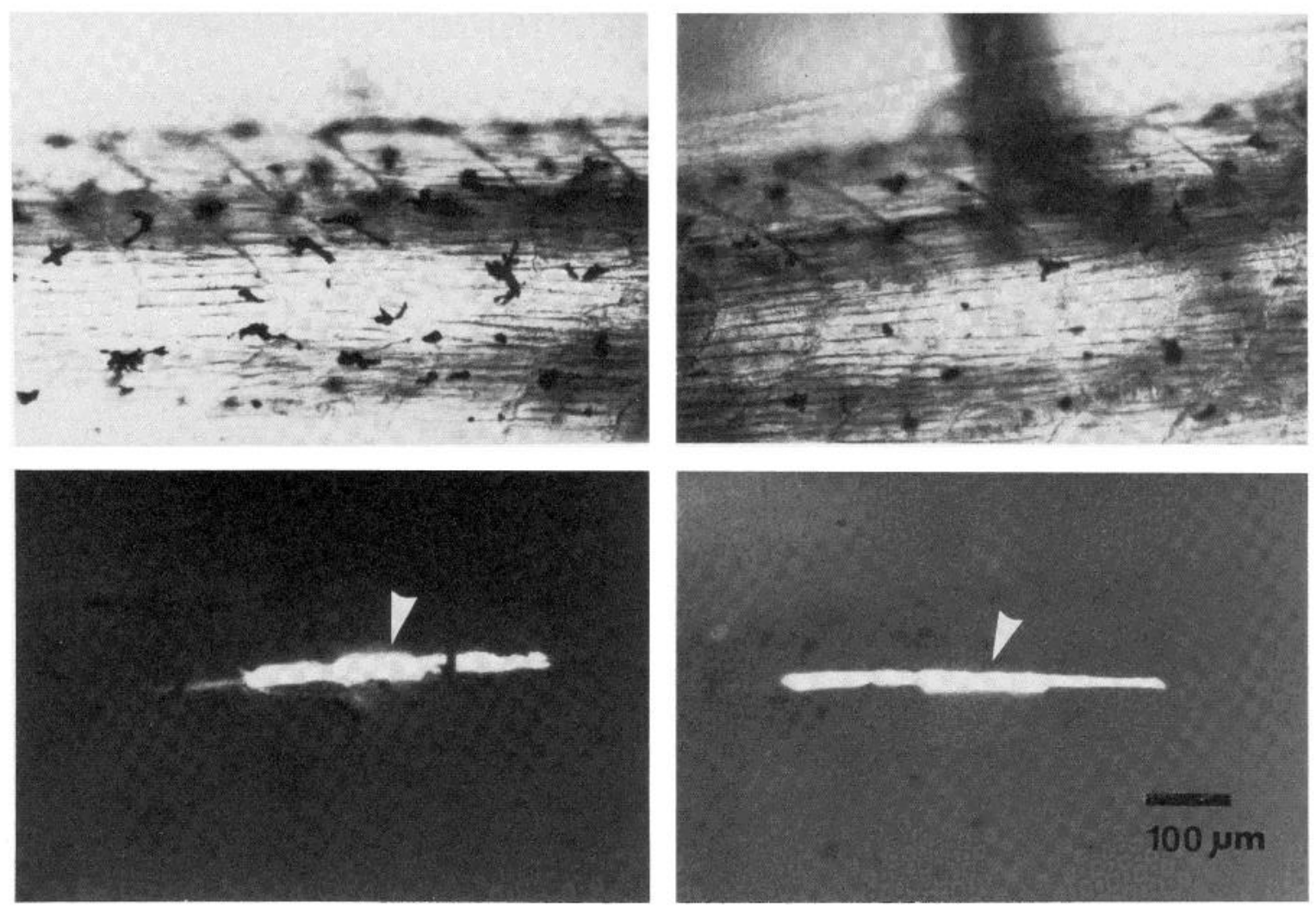

Figure 3. Dye coupling between striated muscle cells in normal Xenopus myotomes at stage 40. Lucifer Yellow was injected into the cells indicated by the arrowheads. Upper photomicrographs: phase contrast view of two preparations. The muscle cells are roughly $100 \mu \mathrm{m}$ in length and are organized into myotomes. Lower photomicrographs: diffusion of Lucifer Yellow viewed with fluorescence in the same field. Magnification $\times \sim 100$.

the embryos begin using their muscle cells repeatedly to produce sustained swimming movements. The possible significance of this temporal relationship was revealed to us by chance.

The role of activity. We routinely anesthetized the embryos with tricaine before sacrificing them and pinning the myotomes out in Ringer's solution. Tricaine rapidly and reversibly abolishes neural activity. We noticed that, at about stage 36 , muscle cells were substantially better coupled in the embryos which had been left in tricaine for several hours than in their counterparts which were exposed to tricaine momentarily. Therefore, we investigated the effects of rearing embryos in tricaine during the period when electrical coupling normally disappears.

Tricaine. Embryos were placed in tricaine between stages 26 and 30, after the rostral myotomes had formed and neuromuscular transmission had begun, and they remained in tricaine past stage 36 . All of the embryos were returned to Ringer's solution without tricaine for measurements of electrical coupling. In contrast to normal embryos at that stage, electrical coupling was detected in all of the tricaine-treated embryos. Treatment with tricaine not only maintains electrical coupling beyond the stage at which it normally disappears but improves the degree of coupling, too. The average mutual resistance was $1.19 \mathrm{mV} / \mathrm{nA}$ between the tricaine-treated myotomes (Table I). Tricaine might improve coupling by increasing the resistance of the nonjunctional membrane,
TABLE I

Electrotonic coupling between myotomes after neuromuscular block

\begin{tabular}{|c|c|c|c|c|c|}
\hline & \multicolumn{2}{|c|}{ Block } & \multirow{2}{*}{ Record } & \multicolumn{2}{|l|}{$\begin{array}{c}\text { Coupling }^{a} \\
(\mathrm{mV} / \mathrm{nA})\end{array}$} \\
\hline & Begin & End & & Mean \pm SD & $n$ \\
\hline \multicolumn{6}{|l|}{ Normal embryos } \\
\hline Untreated & - & - & $\begin{array}{l}26-28^{b} \\
32-35 \\
36-40\end{array}$ & $\begin{array}{l}0.52 \pm 0.26 \\
0.29 \pm 0.16 \\
0.01 \pm 0.03\end{array}$ & $\begin{array}{l}20 \\
15 \\
14\end{array}$ \\
\hline \multirow[t]{3}{*}{ Tricaine $^{c}$} & $26-30^{b}$ & $36-40^{b}$ & $36-40$ & $1.19 \pm 0.41$ & 11 \\
\hline & $26-30$ & 38 & 45 & 0 & 4 \\
\hline & 38 & 45 & 45 & 0 & 7 \\
\hline \multirow[t]{2}{*}{$\alpha$-Bungarotoxin } & $26-28$ & $?$ & $36-40$ & $0.06 \pm 0.09$ & \\
\hline & $26-28$ & 40 & 40 & $1.10 \pm 0.61$ & 4 \\
\hline \multicolumn{6}{|l|}{ Immobile mutants } \\
\hline Untreated & - & - & $36-40$ & $0.04 \pm 0.09$ & 5 \\
\hline Tricaine $^{c}$ & 26 & $38-41$ & $38-41$ & $1.34 \pm 0.93$ & 7 \\
\hline
\end{tabular}

${ }^{a}$ Average mutual resistance of adjacent myotomes in $n$ embryos. Values less than $0.05 \mathrm{mV} / \mathrm{nA}$ could not be detected.

${ }^{b}$ Nieuwkoop and Faber (1956) stages.

${ }^{c}$ Measurements of electrical coupling were made in Ringer's solution without tricaine.

but repeated measurements of mutual resistance during the initial exposure to tricaine revealed no instantaneous improvement in coupling. Inactivity itself also increases muscle membrane resistance (Westgaard, 1975), but widespread electrical coupling does not reappear when the embryos are exposed to tricaine for the first time at 
stage 38. Thus tricaine only prevents the loss of coupling if it is present when the motoneurons begin stimulating the muscle cells to contract repeatedly.

Other properties of the muscle membrane were unaffected by the prolonged exposure to tricaine. The muscle cells retained high resting potentials $(-85$ to $-90 \mathrm{mV})$ throughout the exposure to tricaine. Within $30 \mathrm{~min}$ of their removal from tricaine, the muscle cells were able to spike and respond to acetylcholine. The effect of tricaine on coupling was more slowly reversible, but the electrical coupling eventually disappeared when the embryos were returned to water (Table I); thus it is unlikely that tricaine induces coupling by stimulating cell fusion. These results raise the possibility that neuromuscular activity is required for the elimination of gap junctions between striated muscle cells during development. This hypothesis is substantiated by experiments with a more specific pharmacological probe.

$\alpha$-Bungarotoxin. Embryos were exposed to $\alpha$-bungarotoxin at stage 24 as described under "Materials and Methods." More than $90 \%$ of these embryos recovered movement before stage 36 , and very little electrical coupling could be detected at that time (Table I); however, in those embryos that remained paralyzed until stage 40 , the myotomes were clearly coupled electrically (Fig. 4; Table I). Since $\alpha$-bungarotoxin specifically blocks acetylcholine's ability to activate the cholinergic receptor on skeletal muscle (Chang and Lee, 1963; Miledi and Potter, 1971), this result implies that some consequence of cholinergic activation is required for gap junction elimination.

Immobile mutants. Droin and Beauchemin (1975) have described a lethal recessive mutation in Xenopus which blocks motor activity in early embryos. Apart from their paralysis, the development of these immobile embryos is superficially normal until stage 42 , when their inability to feed and the exhaustion of intracellular yolk granules lead eventually to cell degeneration and death. Silver staining reveals a normal nerve supply to the myotomes, and ultrastructural studies confirm that the muscle cells

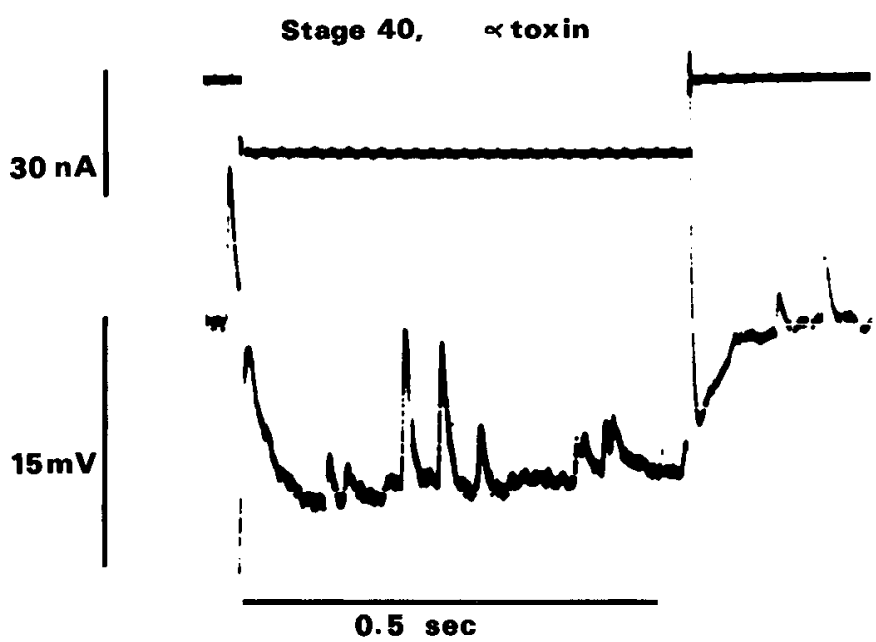

Figure 4. Electrical coupling remaining between striated muscle cells in adjacent myotomes at stage 40 , after exposure to $\alpha$-bungarotoxin during development (see "Materials and Methods"). The Ringer's solution did not contain manganese ions during this recording. contain regular myofibrils which, after extraction, shorten on stimulation with adenosine $5^{\prime}$-triphosphate (Droin and Beauchemin, 1975). Intracellular recordings demonstrate that the innervation is functional: neuromuscular transmission is apparently normal, and the mutant muscle cells are able to generate action potentials (Warner, 1981).

As early as stage 32 , one can record bursts of overshooting action potentials from the striated muscle cells in immobile embryos. Nevertheless, the muscles do not contract, and the embryos do not move. By stage 36 this activity is evident in all of the mutant embryos (Fig. 5). The bursts occur at roughly regular intervals and last for several seconds with 20 to 50 spikes/sec. The spikes are abolished by tubocurarine $(10 \mu \mathrm{M})$, so we presume they are generated by spontaneous neural activity. It is possible that similar bursts of neural activity produce the sustained swimming which appears in normal embryos at this stage of development. Before stage 36 one can also record normal electrical coupling between the myotomes in mutant embryos. This electrical coupling disappears with the same time course as the coupling in normal embryos, even though the mutant muscle cells never contract (Fig. 2). Exposing the mutants to tricaine blocks both the spikes and the loss of electrical coupling (Table I).

\section{Discussion}

We have measured the electrical coupling between striated muscle cells in myotomes of normal Xenopus laevis embryos and in embryos whose activity was suspended during development. Electrical coupling is widespread until the embryos begin sustained and frequent swimming at about stage 36 . This increase in activity in normal embryos is correlated with the onset of neurally evoked bursts of overshooting spikes in the muscle cells of immobile mutants. After stage 36 the incidence of widespread electrical coupling declines precipitously in both normal and mutant embryos. Electrical coupling between cells within the same myotome evidently disappears sometime before the coupling between cells in adjacent myotomes. Some muscle cells remain coupled as late as stage 45 . Pharmacologically blocking neuromuscular transmission delays the loss of electrical coupling within the myotomes.

Electrical coupling between muscle cells in Xenopus myotomes is present as soon as the myotomes are formed (Blackshaw and Warner, 1976). Gap junctions are generally recognized as the membrane structures which allow ions, dyes, and small metabolites to pass directly from one cell's cytoplasm to another (Payton et al., 1969; Kalderon et al., 1977), and there is little doubt that they mediate the electrical coupling which we observe. Gap junctions have been identified in Xenopus myotomes at these stages (Hayes, 1975; Blackshaw and Warner, 1976; Kullberg et al., 1977), and control experiments rule out alternative explanations for the electrical coupling. Electrical coupling between embryonic striated muscle cells seems to be a general feature of vertebrate skeletal muscle development (Dennis, 1981). Since adult skeletal muscle fibers are not connected by gap junctions, two interesting questions present themselves: what role does the coupling play in muscle development and why does 


\section{Immobile, Stage 38}
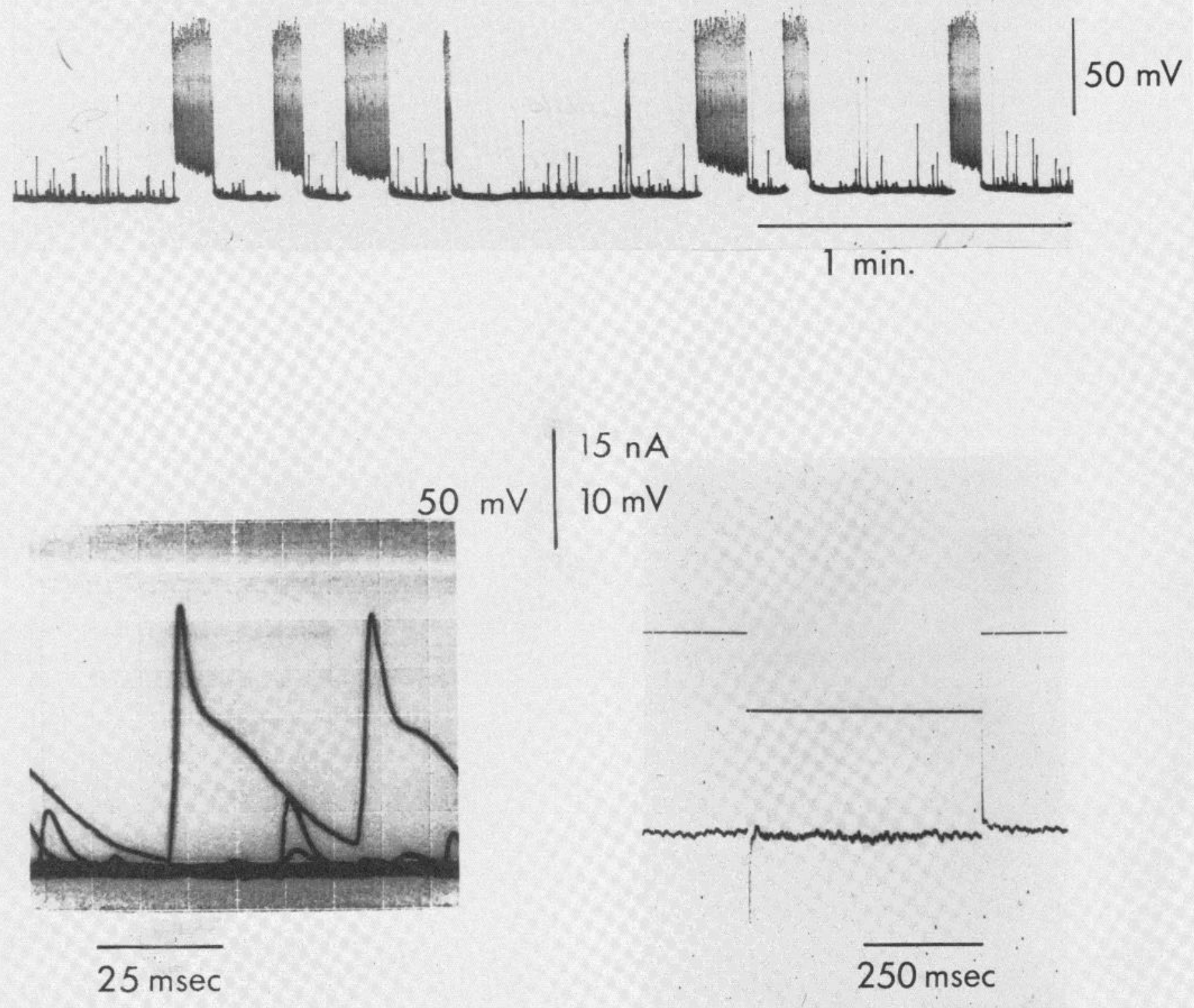

Figure 5. Intracellular recordings from a striated muscle cell in an immobile mutant at stage 38. Manganese ions were only present in the lower right trace. Note the spontaneous bursts of overshooting spikes in the upper trace. Much of the variability in spike amplitude was an artifact of the pen recorder. Several sweeps on a faster time scale are shown at lower left; the spikes decay with a different time course than do the synaptic potentials. No electrical coupling could be detected between adjacent myotomes in this embryo.

it disappear? Our experiments are directed at the mechanism of gap junction elimination.

The relationship between the disappearance of electrical coupling and the elimination of gap junctions is not known. Functional uncoupling can occur without gap junction elimination, as is found in Aplysia (Rayport and Kandel, 1980), as a consequence of a reduction in the resistance of the nonjunctional membrane. However, it is more likely that the loss of electrical coupling which we observe is related to an increase in gap junction resistance. The amplitude of miniature endplate potentials increases as uncoupling proceeds, and at late stages there is a good correlation between the restricted pattern of dye spread and the poor electrical coupling. Nevertheless, some muscle cells remain coupled to adjacent myotomes much later in development. The loss of electrical coupling evidently proceeds faster within myotomes than between them. There is no obvious explanation for this, but the gap junctions also disappear in the same order, both in Xenopus and axolotl myotomes (Hayes, 1975; Keeter et al., 1975).

Muscle activity. In Xenopus embryos, as in other vertebrates (Dennis, 1975; Dennis et al., 1981), the maturation of neuromuscular transmission precedes the loss of electrical coupling during development. Since muscle activity is required for the elimination of both the extra- 
junctional acetylcholine receptors and the supernumerary motor synapses on embryonic skeletal muscle (Dennis, 1981), it is easy to speculate that muscle activity also stimulates the elimination of the gap junctions between developing muscle cells. Our results support this hypothesis; the loss of electrical coupling can be prevented while neuromuscular transmission is blocked pharmacologically with tricaine.

At the same time, we have demonstrated that the loss of widespread coupling within the myotomes proceeds at the normal time in mutant embryos whose muscle cells never contract. Other features of embryonic skeletal muscle also develop normally in cultures of embryonic mouse muscle cells which are unable to contract (Powell et al., 1979). In both of these mutants the muscle cells remain electrically excitable. In the immobile mutants of Xenopus, the múscle cells become electrically excitable early in neuromuscular development (Warner, 1981); nevertheless, there is no decline in the incidence of electrical coupling in the myotomes until the motoneurons begin stimulating the muscle cells repeatedly with regular bursts of activity. The temporal characteristics of this neural activity are very similar to those that were most effective for eliminating extrajunctional acetylcholine receptors by direct electrical stimulation of denervated adult skeletal muscle (Lømo and Westgaard, 1975). Tricaine blocks both the neural activity and the loss of coupling in the immobile mutants. One concludes that the elimination of coupling depends upon repeated muscle stimulation. This may explain the apparent lack of correlation between the development of electrical excitability and the loss of electrical coupling in the embryonic nervous system (Goodman and Spitzer, 1981; Spitzer, 1982).

The effect of activity on the muscle cells is evidently irreversible; once it has disappeared, the widespread electrical coupling cannot be restored by exposing the embryos to tricaine. Morphological studies of Xenopus myotomes confirm that the number of gap junctions decreases during development (Hayes, 1975; Kullberg et al., 1977). Since neuromuscular block with $\alpha$-bungarotoxin during that period in development also prevents the loss of electrical coupling, this implies that gap junction elimination depends on some consequence of acetylcholine binding. Muscle excitation is the most obvious consequence of cholinergic activation, but there are examples of acetylcholine action which cannot be reproduced by direct electrical stimulation of the postsynaptic cell (Parnas et al., 1974; Mathers and Thesleff, 1978; Chalazonitis and Zigmond, 1980). In other systems the gap junctions' conductance can be reduced by a variety of experimental perturbations. Acetylcholine reversibly uncouples acinar cells in the pancreas (Iwatsuki and Petersen, 1978). Increases in the transjunctional voltage (Spray et al., 1981) or the intracellular concentration of hydrogen or calcium ions also uncouple cells in several vertehrate embryos (Turin and Warner, 1980; Bennett et al., 1981). All of these events may be associated with neuromuscular transmission, but it remains to be determined whether the repeated presentation of such perturbations could result in the elimination of the gap junctions altogether. In this regard it is interesting that the degree of electrical coupling measured by the mutual resistance after pro- longed neuromuscular blockade is substantially higher than that observed at early developmental stages (Table I). This implies some effect of neuromuscular activity on gap junction permeability early on in neuromuscular junction formation, and raises the possibility that imposition of rapid stimulation early in development might hasten the elimination of electrical coupling.

Gap junctions and muscle development. The functional role of electrical coupling between developing striated muscle cells is not known. In vitro studies of muscle development have focused on the gap junctions between myoblasts and their possible role in myotube formation (Rash and Fambrough, 1973; Kalderon et al., 1977), but recently, another cell organelle has been implicated in the process of myoblast fusion (Kalderon and Gilula, 1979). In vivo, there is less correlation between gap junction formation and myoblast fusion. In Xenopus myotomes, many of the gap junctions disappear before cell fusion begins. In other species where fusion occurs earlier in development, the myotubes remain connected by gap junctions (Keeter et al., 1975; Schmalbruch, 1982). Several authors have proposed that this electrical coupling might allow coordinated reflex responses before innervation is established.

It is also possible that early muscle activation is required for normal cellular differentiation. Motoneurons control the expression of many muscle cell proteins by regulating the pattern of muscle activity during development (reviewed by Vrbová et al., 1978). Gap junction elimination would be a prerequisite for such control; otherwise all the muscle cells would experience the same pattern of electrical activity. Now that the normal elimination of gap junctions can be delayed experimentally, these ideas can be pursued with further experiments.

\section{References}

Armstrong, D. L., and A. E. Warner (1980) On the elimination of gap junctions between developing muscle cells. J. Physiol. (Lond.) 300: 64P.

Bennett, M. V. L., D. C. Spray, and A. L. Harris (1981) Electrical coupling in development. Am. Zool. 21: 413-427.

Blackshaw, S. E., and A. E. Warner (1976) Low resistance junctions between mesoderm cells during development of trunk muscles. J. Physiol. (Lond.) 255: 209-230.

Burden, S. (1977) Development of the neuromuscular junction in the chick embryo: The number, distribution and stability of acetylcholine receptors. Dev. Biol. 55: 317-329.

Chalazonitis, A., and R. E. Zigmond (1980) Effects of synaptic and antidromic stimulation on tyrosine hydroxylase activity in the rat superior cervical ganglion. J. Physiol. (Lond.) 300: 525-538.

Chang, C. C., and C. Y. Lee (1963) Isolation of neurotoxins from the venom of Bungarus multicintus and their modes of neuromuscular blocking action. Arch. Int. Pharmacodyn. Ther. 144: 241-257.

Dennis, M. J. (1975) Physiological properties of junctions between nerve and muscle developing during salamander limb regeneration. J. Physiol. (Lond.) 244: 683-702.

Dennis, M. J. (1981) Development of the neuromuscular junction: Inductive interactions between cells. Annu. Rev. Neurosci. 4: 43-68.

Dennis, M. J., and C. A. Ort (1977) The distribution of acetylcholine receptors on muscle fibers of regenerating salamander limbs. J. Physiol. (Lond.) 266: 765-776.

Dennis, M. J., I. 7iskind-Conhaim, and A. „J. Harris (1981) 
Development of neuromuscular junctions in rat cmbryos. Dev. Biol. 81: 266-279.

Detwiler, P. B., and A. L. Hodgkin (1979) Electrical coupling between cones in turtle retina. J. Physiol. (Lond.) 291: 75100.

Diamond, J., and R. Miledi (1962) A study of foetal and newborn rat muscle fibers. J. Physiol. (Lond.) 162: 393-408.

Droin, A., and M. L. Beauchemin (1975) Immobile (im), a recessive lethal mutation of Xenopus laevis tadpoles. J. Embryol. Exp. Morphol. 34: 435-449.

Goodman, C. S., and N. C. Spitzer (1981) The development of electrical properties of identified neurones in grasshopper embryos. J. Physiol. (Lond.) 313: 385-403.

Gordon, T., and G. Vrbová (1975) Changes in chemosensitivity of developing chick muscle fibers in relation to endplate formation. Pflugers Arch. 360: 349-364.

Harris, W. A. (1981) Neural activity and development. Annu. Rev. Physiol. 43: 689-710.

Harrison, R. G. (1904) An experimental study of the relation of the nervous system to the developing musculature in the embryo of the frog. Am. J. Anat. 3: 197-220.

Hayes, B. P. (1975) The distribution of intercellular junctions in the developing myotomes of the clawed toad. Anat. Embryol. 147: 345-354.

Iwatsuki, N., and O. H. Petersen (1978) Pancreatic acinar cells: Acetylcholine evoked uncoupling and its ionic dependency. J. Physiol. (Lond.) 274: 81-96.

Kalderon, N., and N. B. Gilula (1979) Membrane events involved in muscle fusion. J. Cell Biol. 81: 411-425.

Kalderon, N., M. L. Epstein, and N. B. Gilula (1977) Cell-tocell communication and myogenesis. J. Cell Biol. 75: 788-806.

Keeter, J. S., G. D. Pappas, and P. G. Model (1975) Inter- and intramyotomal gap junctions in the axolotl embryo. Dev. Biol. 45: 21-33.

Kelley, A. M., and S. I. Zacks (1969) The histogenesis of rat intercostal muscle. J. Cell Biol. 42: 135-153.

Kullberg, R. W., T. L. Lentz, and M. W. Cohen (1977) Development of the myotomal neuromuscular junction in Xenopus laevis: An electrophysiological and fine structural study. Dev. Biol. 60: 101-129.

Lømo, T., and R. H. Westgaard (1975) Further studies on the control of ACh sensitivily by activity in the rat. J. Physiol. (Lond.) 252: 603-626.

Mathers, D. A., and S. Thesleff (1978) Studies on neurotrophic regulation of murine skeletal muscle. J. Physiol. (Lond.) 282: 105-114.
Miledi, R., and L. T. Potter (1971) Acetylcholine receptors in muscle fibers. Nature 233: 599-603.

Muntz, L. (1975) Myogenesis in the trunk and leg during development of the tadpole of Xenopus laevis (Daudin 1802). J. Embryol. Exp. Morphol. 33: 757-774.

Nieuwkoop, P. D., and J. Faber (1956) Normal Table of Xen opus laevis, Elsevier North-Holland, Amsterdam.

Parnas, I., D. Armstrong, and F. Strumwasser (1974) Prolonged excitatory and inhibitory synaptic modulation of a bursting pacemaker neuron. J. Neurophysiol. 37: 594-608.

Payton, B. W., M. V. L. Bennett, and G. D. Pappas (1969) Permeability and structure of membranes at an electrotonic synapse. Science 166: 1641-1643.

Powell, J. A., B. A. Friedmann, and A. Cossi (1979) Tissue culture study of murine muscular dysgenesis: Role of spontaneous action potential generation in the regulation of muscle maturation. Ann. N. Y. Acad. Sci. 317: 550-570.

Rash, J. E., and D. Fambrough (1973) Ultrastructural and electrophysiological correlates of cell coupling and cytoplasmic fusion during myogenesis in vitro. Dev. Biol. 30: 166-186.

Rayport, S. G., and E. R. Kandel (1980) Developmental modulation of an identified electrical synapse: Functional uncoupling. J. Neurophysiol. 44: 555-567.

Schmalbruch, H. (1982) Skeletal muscle fibers of newborn rats are coupled by gap junctions. Dev. Biol. 91: 485-490.

Spitzer, N. C. (1982) Voltage- and stage-dependent uncoupling of Rohon-Beard neurones during embryonic development of Xenopus tadpoles. J. Physiol. (Lond.) 330: 145-162.

Spray, D. C., A. L. Harris, and M. V. L. Bennett (1981) Equilibrium properties of a voltage-dependent junctional conductance. J. Gen. Physiol. 77: 77-93.

Stewart, W. W. (1978) Functional connections between cells as revealed by dye-coupling with a highly fluorescent napthalimide tracer. Cell 14: 741-759.

Turin, L., and A. E. Warner (1980) Intracellular pH in early Xenopus embryos: Its effect on current flow between blastomeres. J. Physiol. (Lond.) 300: 489-504.

Vrbová, G., T. Gordon, and R. Jones (1978) Nerve-Muscle Interaction, Chapman Hall, London.

Warner, A. E. (1981) Electrical properties of muscles from an immobile mutant of Xenopus laevis. J. Physiol. (Lond.) 312: $30 \mathrm{P}$.

Westgaard, R. H. (1975) Influence of activity on the passive electrical properties of denervated soleus muscle fibres in the rat. J. Physiol. (Lond.) 251: 683-697. 